Journal of The Magnetics Society of Japan Vol. 13, Supplement, No. S1 (1989)

(c) 1989 by The Magnetics Society of Japan

\title{
HEAT TREATMENT EFFECT OF CO-Cr FILM ON READ-WRITE CHARACTERISTICS
}

\section{Kazuetsu YOSHIDA*, Kazushige IMAGAWA* Fumio KUGIYA *, Hideo DAIMON **, Satoshi YAMAGATA**, Osamu KITAKAMI**, and Hiroshi YASUOKA***}

*Central Research Laboratory, Hitachi, Ltd., Kokubunji, Tokyo, 185 Japan

**Tsukuba Research Laboratory, Hitachi Maxell, Ltd., Mitsukaido, Ibaraki, 300-25 Japan

***The Institute for Solid State Physics, The University of Tokya,

Roppongi Minatoku, Tokyo, 113 Japan

The read-write characteristics of a $\mathrm{Co}-\mathrm{Cr}$ film are improved by heat treatment in a vacuum. Although magnetic properties are hardly affected by heat treatmnent, the microstructure of a $\mathrm{Co}-\mathrm{Cr}$ film changes differently between samples with and without a Ge layer. However. the crystallinity of $\mathrm{Co}-\mathrm{Cr}$ films is confirmed to be improved by heat treatment, regardless of the presence of a Ge layer, using a transmission electron microscope, an X-ray diffraction meter and NMR method. Thus, read-write characteristics are shown to closely relate to film crystallinity.

\section{INTRODUCTION}

Perpendicular magnetic recording (1) is a promising technique for use as extreamely high recording density file memory. Numerous experiments show that perpendicular magnetic recording has the ability to exceed a linear bit density of $200 \mathrm{kFCI}$ and realize an ultra-narrow bit area recording of less than $14 \mathrm{~m}^{2}$ [2] [4]. However, at an ultrahigh recording density, the signal output becomes too small for correct operation. Therefore, a method for making the signal output as large as possible is required.

In this study, the relationship between the crys talline micros tucture and read - write characteristics of a $\mathrm{Co}-\mathrm{Cr}$ film is discussed. Read-write characteristics are improved by heat treatment. The cause of the improvement has been investigated in connection with microstructural change.

\section{EXPERIMENTAL PROCEDURE}

\section{Sample preparation}

Co-Cr films were prepared with a vacuum evaporation method using a roll coater and winding a base film. The base film was a polyimide tape 50 \&m-thick, which was degassed by rolling it over a hot roller heated at $265^{\circ} \mathrm{C}$ before deposition. A Co-Cr film $0.3 \mu \mathrm{m}$ - thick was formed on a Ge layer, after a Ge underlayer $30 \mathrm{~nm}$-thick was deposited on the base film, to promote c-axis orientation. A Co-Cr film without a Ge layer was also prepared for reference. The vacuum pressure during a depositon was approximately $2 \times 10^{-3} \mathrm{~Pa}$, the deposition rate of Co-Cr was from 100 to $260 \mathrm{~nm} / \mathrm{s}$ and the roll surface temperature was from 160 to $265^{\circ} \mathrm{C}$.

Measurement of magnetic properties

Saturation magnetization (Ms), coercivity $(\mathrm{Hc})$, and squareness (S) were measured us ing a VSM (vibrating sample magnetometer) with a maximum magnetic field of $800 \mathrm{kA} / \mathrm{m}$. The magnetic properties measured with the magnetic fields applied in the sample planes are denoted by the suffix, and those measured with magnetic fields applied normal to the planes by the suffix 1 .

A perpendicular magnetic anisotropy ( $\mathrm{Ku}$ ) was obtained by adding shape magnetic anisotropy $\left(=1 / 2 \mu_{\mathrm{o}} \mathrm{Ms}^{2}\right)$ to an apparent anisotropy which was obtained directly from the amplitude of the magne to-torque curve. 
Spatial distribution of Co and Cr atoms

The NMR (nuclear magnetic resonance) measurement of the hyperfine fields at the nuclei in ferromagnetic alloys is a powerful method for estimating how $\mathrm{Cr}$ atoms are distributed around Co atoms [5]. Sample films were cooled at $4.2 \mathrm{~K}$ and the spin-echo method was used for the observation of NMR signals.

Read - Write Characteris tics

The read-write $(\bar{R} / W)$ characteristics were measured using a $2^{*}$ diameter stretch-type disk which was punched out of a tape. The magnetic head used was the composite ring type made of $\mathrm{Co}-\mathrm{Nb}-\mathrm{Zr}$ amorphous film and $\mathrm{Mn}-\mathrm{Z}_{\mathrm{n}}$ ferrite blocks. The heads gap length was $0.25 \mu \mathrm{m}$. A $20 \mathrm{~nm}$-thick protective layer and liquid lubricant were used for avoiding head crash.

Observation of crystalline microstrucure

Cross-sectional microstructure of a $\mathrm{Co}-\mathrm{Cr}$ film was examined using a Hitachi $H-800$ transmission electron microscope (TEM. acceleration voltage: $200 \mathrm{keV}$ ). Samples were prepared for TEM observation by the ion thinning method.

The crystalline $c$-axis orientation and the crystallinity were estimated with the full width at half the maximum of an X-ray reflection rocking curve of the $(002)$ plane and the peak height of the 002 diffraction, respectively.

\section{RESULTS}

Change of $R / W$ characteristics by heat treatmen $t$

The $\bar{R} / W$ characteristics of a Co-Cr film were markedly improved by heat treatment at $400 \mathrm{r}$ in a vacuum. The $\mathrm{R} / \mathrm{W}$ characteristics of as-deposited and heat-treated samples with a Ge underlayer (A) and without it (B) are presented in Figs. 1(a) and (b), respectively. The signal outputs of both the samples increase by $2 \sim 5 \mathrm{~dB}$ and the halfmaximum recording density $\left(D_{50}\right)$ is also improved. The $D_{50}$ of sample $(A)$ increases

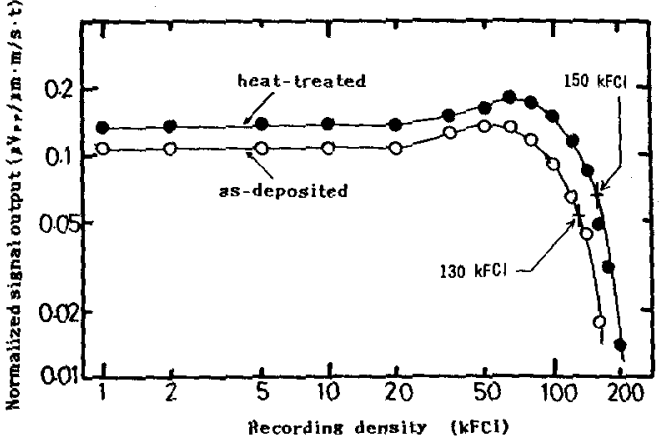

(a) sample A with Ge underlayer

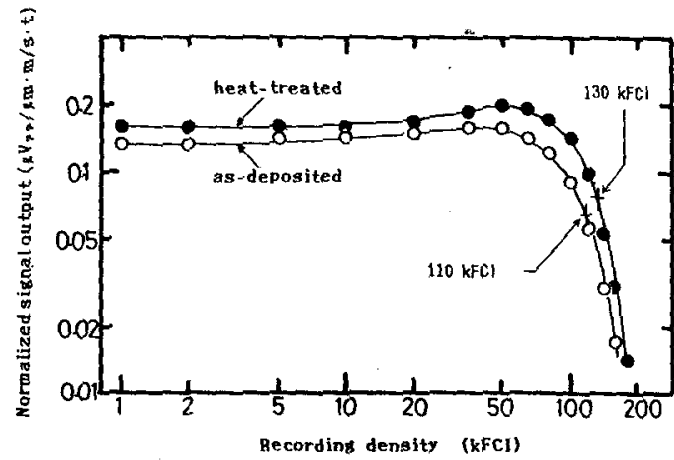

(b) sample B without Ge underlayer

Fig. 1. Output dependence on recording density.

from 130 to $150 \mathrm{kFC} \mathrm{I}$ and that of sample (B) from 110 to $130 \mathrm{kFCI}$.

The perpendicular magnetization curves before and after heat treatment are presented in Fig. 2. For sample (A), the Ms markedly decreases and the Hcl increases slightly. On the contrary, the Ms scarcely decreases and the $\mathrm{HCl}$ decreases slightly for sample (B). The perpendicular anisotropy $(\mathrm{Ku})$ of sample (A) and (B) decreased due to the decrease in Ms in the measurement of magne to-torque curve. However, the $Q$ values $\left(=\mathrm{Ku} / 1 / 2 \mu_{0} \mathrm{Ms}_{s}^{2}\right.$ ) increased for both the samples, which indicates that the net perpendicular anisotropy was increased by heat treatment.

It is well known that the signal output of 


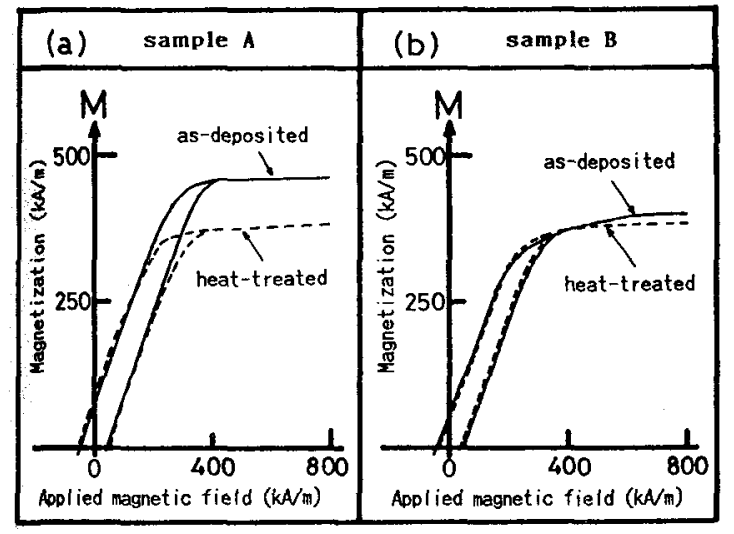

Fig. 2. Magnetization curve before and after heat treatment.

a Co-Cr film strongly depends on the $\mathrm{Hc} \perp$ for a combination of $\mathrm{Co}-\mathrm{Cr}$ single layer and ring type head[6]. The larger the $H c \perp$ is, the larger the output is. Therefore, the output increase in sample (A) could be explained by the $\mathrm{Hcl}$ increase. However, for sample (B), the output increased, in spite of the decrease in the $\mathrm{HcL}$. Thus, this suggests that the improvement of the $\mathrm{Co}-\mathrm{Cr}$ film $\mathrm{R} / \mathrm{W}$ characteristics by heat treatment are related to crystallographical changes in film microstructure, rather than in magnetic properties.

In the next section, the microstructure and the crystallinity of the as-deposited and heat-treated samples are investigated using TEM and an $\mathrm{X}$-ray diffraction method.

Microstructure of as-deposited and heattreated film

The cross-sectional images and electron diffraction patterns of sample (A) and (B) are presented in Figs. 3 and 5 , respective1y. For sample (A) with a Ge underlayer, the as-deposited film is composed of columnar grains approximately $50 \mathrm{~nm}$-wide. Many horizontal stripes, which are thought to be stacking faults, are present. The diffraction pattern shows that the crystal structure is hcp and its c-axis preferentially orients in the vertical direction of the film, because 002 diffraction spots concen-

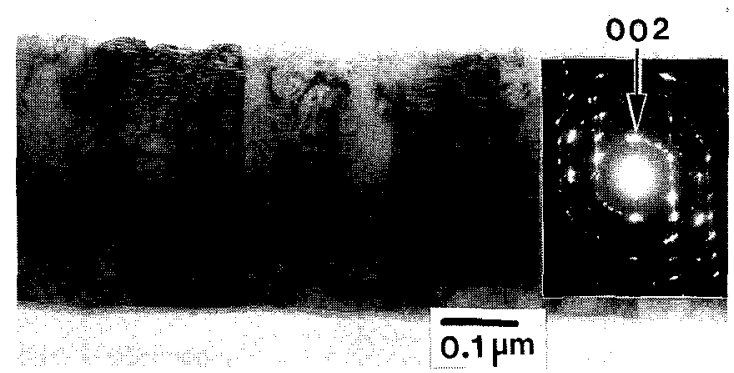

(a) as-deposited film

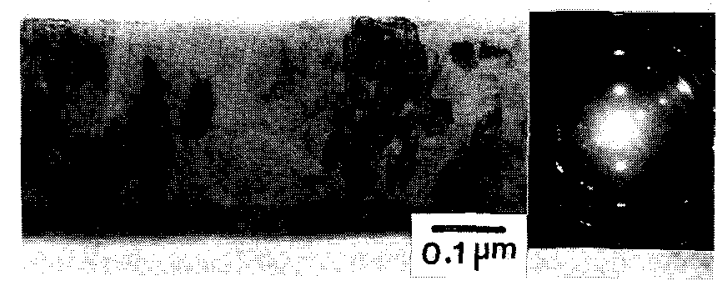

(b) heat-treated film at $400^{\circ} \mathrm{C}$ in vacuum

Fig. 3. Cross-sectional structure of $\mathrm{Co}-\mathrm{Cr}$ film with Ge underlayer (sample A) before and after heat treatment.

trate in the vertical direction of the film. The c-axis preferential orientation was also supported by the $\Delta \theta_{50}$ of $6^{\circ}$.

Sample (A) was heat-treated at $400 \mathrm{r}$ in a vacuum and significant change occurred. Here, the grain boundaries which appeared in the as-deposited film vanish and the film becomes very uniform, as shown in Fig. 3(b).

This result shows that $\mathrm{Co}$ and $\mathrm{Cr}$ atoms diffused through the grain boundary and the grains grew. This microstructural change results in a very simple electron diffraction pattern, indicating that the film resembles single crystal in the region of the electron beam spot $(\sim 0.5 \mu \mathrm{m})$. Here, the spots which line up in the $45^{\circ}$ direction 


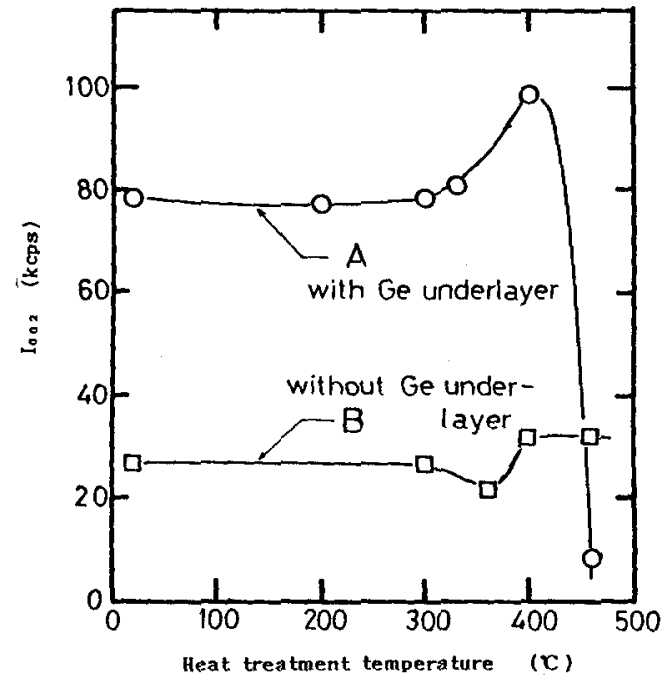

Fig. 4. I0oz dependence on heat treatment temperature.

were assigned to the diffraction from 111 of the Ge underlayer having a diamond structure crystallized by heat treatment.

The diffraction intensity $\left(\mathrm{I}_{0} 0_{2}\right)$ dependence on heat treatment temperature is presented in Fig. 4. The Iooz of sample (A) increases above $300 \mathrm{C}$ and reaches a maximum at $400 \mathrm{r}$, then decreases abruptly. This results from Figs. 3 and 4 show that the crystallinity was improved by the heat treatment at $400 \mathrm{c}$. In addition, the abrupt decrease in the $I_{002}$ above 400 c, shown in Fig. 4 , is due to the formation of a Ge and Co compound by heat treatment.

The microstrucure of sample (B) without a Ge underlayer is presented in Fig. 5. The cross-sectional structure of sample (B) is also columnar, like sample $(A)$. However, the columnar size of sample (B) disperses from 20 to $50 \mathrm{~nm}$, much more than that of sample (A). Additionally, the electron diffraction pattern is ring-like, indicating that the $c$-axis orientation is not as good as in sample (A). The $\Delta \theta_{50}$ was $9^{\circ}$ wider than that of sample (A).

When sample $(B)$ is heat-treated, the microstructural changes differently from

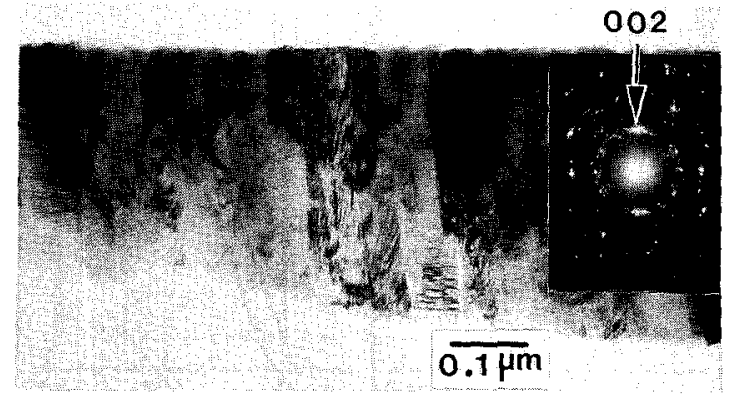

(a) as-deposited film

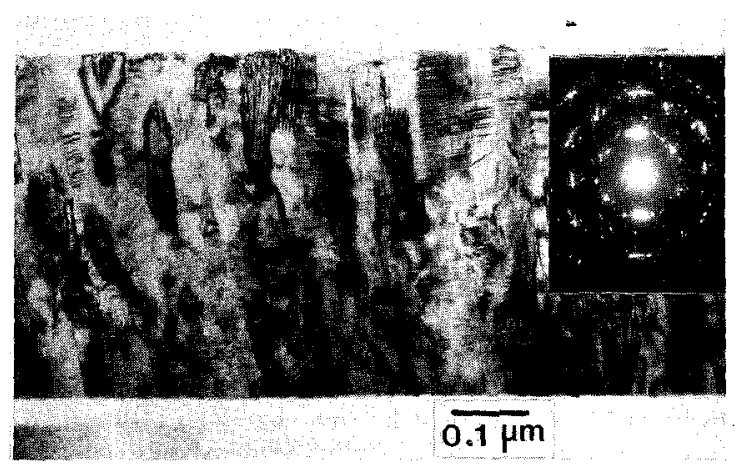

(b) heat-treated film at $400^{\circ} \mathrm{C}$ in vacuum

Fig. 5. Cross-sectional structure of $\mathrm{Co}-\mathrm{Cr}$ film without Ge underlayer (sample B).

in sample (A), as shown in Fig. 5(b). The grain boundaries do not vanish because of heat treatment, but ra ther become more clear. Moreover, each column has dark and bright contrast which is not so clear in the asdeposited film. This result indicates that the columns are composed of micro-crystallites which have different crystallographic directions. However, the 002 electron diffraction spots in Fig. 5 (b) and the $I_{002}$ in Fig. 4 become stronger than those of the as-deposited film because of heat treatment, indicating that the crystallinity was improved, too. Here, the $\mathrm{I}_{002}$ of sample (B) in Fig 4 is not decreased by heat treatment over $400 \mathrm{r}$, because of the lack of a Ge underlayer. 
NMR spectrum of $\mathrm{Co}-\mathrm{Cr}$ Film

In a $\mathrm{Co}-\mathrm{Cr}$ film, the internal magnetic field depends on the coordination number of the $\mathrm{Cr}$ atoms around a Co atom. That is, the resonance frequency, which is proportinal to the internal magnetic field, decreases with an increased $\mathrm{Cr}$ atom coordination number.

The spin-echo spectra of a Co-22at\% $\mathrm{Cr}$ film with a Ge underlayer, which was deposited at $160 \mathrm{C}$, are presented in Fig. 6. The spin-echo spectrum of the as-deposited film (Fig. 6(a)) consists of an intense main line at $157 \mathrm{MHz}$ and six relatively weak lines distributed around the main line. This spectrum was completely different from that of a bulk $\mathrm{Co}-22 \mathrm{at} \% \mathrm{Cr}$ alloy which has an intense main line approximately at $45 \mathrm{MHz}$. Further, it was confirmed that the intense line at $157 \mathrm{MHz}$ was attributed to that of approximately 10 at\% $\mathrm{Cr}$ alloy rather than that of 22 at\% $\mathrm{Cr}$ alloy [7].

This result clearly shows the segregation of $\mathrm{Cr}$ atoms in a $\mathrm{Co}-\mathrm{Cr}$ film and also shows that the $\mathrm{Cr}$ concentration in the $\mathrm{Cr}$ poor region is approximately $10 \mathrm{at} \%$. Moreover, the absorption line at $207 \mathrm{MHz}$ could be attributed to the Co atoms around which no $\mathrm{Cr}$ atoms coordinate.

When the $\mathrm{Co}-\mathrm{Cr}$ film was heat-treated at $400 \mathrm{C}$ in a vacuum, the spectrum changed, as shown in Fig. 6(b). Specifically, the absorption line at $207 \mathrm{MHz}$ decreased and split into three weaker lines. On the other hand, the absorption intensities at frequencies lower than $150 \mathrm{MHz}$ increase slightly. These results indicate that the region in which $\mathrm{Co}$ atoms are not coordinated by any Cratoms is heat-unstable and disappears through the diffusion of $\mathrm{Co}$ and $\mathrm{Cr}$ atoms due to heat treatment. Also, the disappearance of this region results in the decrease in the Ms, as shown in Fig. 2(a).

\section{DISCUSSION}

Although the relationships between $\mathrm{Co}-\mathrm{Cr}$ film microstructure and $\mathrm{R} / \mathrm{W}$ characteristics have not yet been clarified, experimental

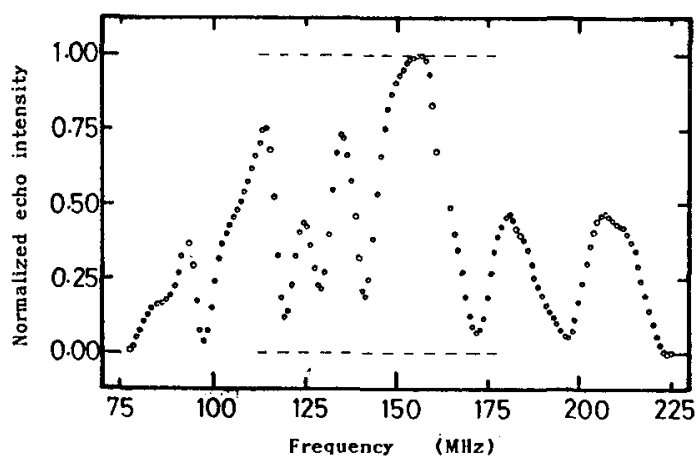

(a) as-deposited film

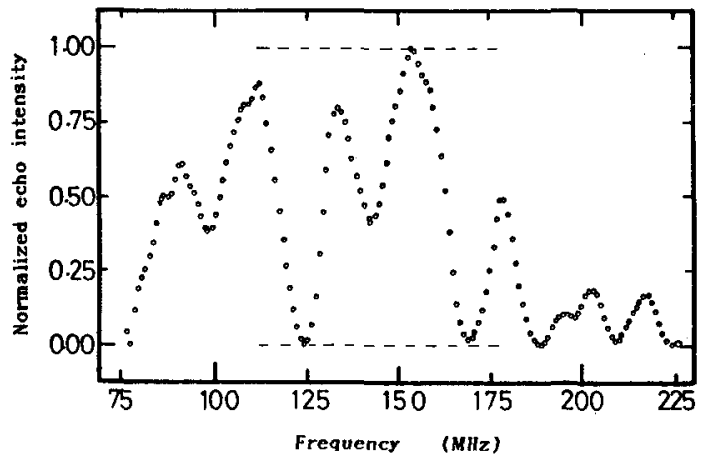

(b) heat-treated film

Fig. 6. Spin-echo spectrum of $\mathrm{Co}-\mathrm{Cr}$ film before and after heat treatment.

results indicate that the Co-Cr films with a clear columnar structure have excellent $\mathrm{R} / \mathrm{W}$ characteristics [4]. The samples used in this study had columnar structure in the as-deposited state. However, the columnar structure was eliminated in sample (A), but not in sample (B), by heat treatment. On the other hand, the $\mathrm{R} / W$ characteris tics were improved in both samples. These results suggest that the columnar structure of a $\mathrm{Co}-\mathrm{Cr}$ film does not relate to the $R / W$ characteristics. The experimental results mentioned in the previous section showed that the crystallinity of both $\mathrm{Co}-\mathrm{Cr}$ films was improved by heat treatment. Therefore, it is thought that the crystallinity colsely relates to the $\mathrm{R} / \mathrm{W}$ characteristics of a $\mathrm{Co}-\mathrm{Cr}$ film, rather than the columnar structure. 
This reason is considered as follows.

In perpendicular magnetic recording, the intensity of the magnetic field induced by a magnetic head decreases abrupty as the dis tance from the head surface increases. Therefore, it is though that the magnetization switches successively from the surface to the bottom of a $\mathrm{Co}-\mathrm{Cr}$ film. Thus, crystallographical continuity in the direction from the surface to the bottom of a $\mathrm{Co}-\mathrm{Cr}$ film, i.e. excellent crystallinity, is thought to be an important factor in promoting this swtching in perpendicular magnetic recording media.

\section{SUMMARY}

The relationships between the microstructure of a $\mathrm{Co}-\mathrm{Cr}$ film and its read-write characteristics were studied by investigating the changes in the microstructure and the read-write characteristics before and after heat treatment. The results obtained in this study were as follows:

1) The read-write characteristics were improved by heat treatment.

2) Although the magnetic properties hardly changed due to heat treatment, the microstructure of the $\mathrm{Co}-\mathrm{Cr}$ films changed differently in the sample with a Ge underlayer and the sample without it.

3) It was confirmed that the spatial distribution of $\mathrm{CO}_{\mathrm{O}}$ and $\mathrm{Cr}$ atoms changed by heat treatment, using a NMR method.

4) The crystallinity of a $\mathrm{Co}-\mathrm{Cr}$ film was shown to be improved by heat treatment, by observing a cross-sectional structure and by using the $X$-ray diffraction method. 5) It was concluded that the crystallinity improvement resulted in the improvement of $R / W$ characteristics.

\section{AKNOWLEDGEMENTS}

The authors would like to express sincere thanks to Dr. Tsuneo Suganuma for his encouragement. They are also indebted to $\mathrm{Dr}$. Hiroshi Kakibayashi of Hitachi's Central Research Laboratory and Mr. Teruho Shimotsu of Hitachi Engineering, Ltd. who took the cross-sectinal photographs, and Dr. Masaaki Futamoto and Mr. Yukio Honda for their helpful discussion.

\section{REFERENCES}

[1] S. Iwasaki and Y. Nakamura, IEEE Trans.u Magn. MAG-13(1977)1272.

[2] M. Futamoto, Y. Honda, H. Kakibayashi and K. Yoshida, IEEE Trans. Magn. MAG-21 (1985) 1426 .

[3] S. Yamamo to, Y. Nakamura and S. IW asaki, IEEE Trans. Magn. MAG-23(1987) 2070.

[4] R. Sugita, T. Nambu and Y. Sakamoto, IEEE Tans. Magn. MAG-23(1987)2449.

[5] S. Kobayashi, K. Asayama, and J. Itoh, J. Phys. Soc. Japan, 21(1966)65.

[6] J. Hokkyo, K. Hayakaya, I. Saito, S. Satake, K. Shirane, N. Honda, T. Shimaura, and, T. Saito, IEEE Trans. Magn. MAG-18 (1982) 1203.

[7] K. Yoshida, and H. Yasuoka, to be published. 